\title{
The Impact of Self Help Group Approach in the Lives of Beneficiaries at Household Level: The Case of Children's Home Society and Family Services, Hosanna Family Empowerment Program
}

\author{
Fekadu Negusie \\ Bethany Christian Services Global, LLC, Addis Ababa, Ethiopia \\ fekadunegusie@yahoo.com
}

\begin{abstract}
The study was conducted to find out the impacts of Self Help Groups (SHGs) Approach in the lives of beneficiaries at household level: in case of Hosanna Family Empowerment Program which is part of the development projects of Children's Home Societies and Family Services (CHSFS). Children's Home Society and Family Services (CHSFS) is one of the international not-for profit organizations in Ethiopia which are promoting SHG approach as a model for transformational development. Self-Help Group is an informal association of people in a village, hamlet or urban neighborhood with the principal objective of empowering destitute women economically, socially, politically, institutionally and spiritually. The researcher focused on analyzing the significant impacts of SHGs compared to other developmental endeavors undertaken by the organization under the study with the following specific objectives in mind:

- To investigate if the economic aspects of the beneficiaries at household level demonstrated improvement

- To assess if SHG approach has brought the desired results on the lives of the beneficiaries in the social, political and leadership aspects of their lives.

- To recommend if SHG could be adopted as a development model for mitigating poverty at the national level.

The researcher used questionnaire for educated respondents and scheduled interview for illiterate respondents. In order to enhance the validity of the research, both qualitative and quantitative methods were applied in the research. The analysis of the findings of the research reveals that involvement in SHGs has significant economic and social contributions on the lives of poor women.
\end{abstract}

Keywords: Self Help Group, House Hold Level, Home Society

\section{Introduction}

Background to the Study: This study was conducted in Southern Nation and Nationalities Regional State (SNNPR), Hadiya Zone, Hosanna town in the following Kebeles: Licha Amba (5 SHGs), Mealanba (2 SHGs), Jelo Naramo (3 SHGs), Bethel (1SHG) and Sech Duna (1 SHG). The study examines the impact of SHG approach on beneficiaries at household level that CHSFS is undertaking in Hosanna town. Hosanna is one of the lowest urbanized zonal towns in Ethiopia and the slowest growing business and industrial towns in the country where there are many social problems prevailing. A survey commissioned by CHSFS in 2008 reveals that the "level of urbanization in Hadiya Zone is one of the lowest in Ethiopia, only about 8.3 percent, which is far cry from the corresponding figure of the nation which is not less than 17 percent"(Solomon, 2008 PP 133). Solomon indicates in the survey that movement within the Hadiya Zone or even out of the Zone is one of the contributing factors that affect the growth of Hosanna town. It was indicated in the study that "the residents of Hosanna town are quite mobile, going elsewhere in search of education or jobs and then returning to the town because of their love to their place of birth. The survey indicates that lack of jobs in other places, inability to adjust to other places and work-related transfers including returning to the town in retirement age were among the leading factors bringing the people back to their town"(Solomon, 2008 PP 139). The town is inundated with many social and economic problems some of which are unemployment, destitution, lack of income, poor housing conditions, poor health conditions, lack of tarred roads, and lack of access to basic facilities such as potable water, electric power, hotels and restaurants. Quite a number of researchers have indicated in their studies that SHG has both social and economic benefits in terms of curbing these alarming shortcomings. This research is designed to figure out whether the aforementioned benefits are truly gained by Hosanna Self Help Group members organized under CHSFS. 
Problem Statement/Justification or Research Rationale: Self-Help Group is an informal association of people in a village, hamlet or urban neighborhood with the principal objective of empowering destitute women economically, socially, politically, institutionally and spiritually. The following are the specific objectives of SHG

- To raise funds for day today needs. The saving groups when transformed to earning groups not only increase the productivity of women but the credibility also.

- To maintain family structure through availing economical solutions to the families in times of their needs.

- To protect the exploitation of women from loan sharks.

- To ensure development of self-confidence among SHG members

- To create a common platform for a dialogue and sharing of views

- To groom the groups to be cohesive and participative.

- To enable the members to pool their savings regularly.

- To empower the women to participate in society and be a participant in sustainable development

- To motivate members to make interest bearing small loans to one another.

- To reach microfinance services to the poor, through an organized and systematic use of homogeneous groups as base level units

It is generally believed among SHG implementing organizations that SHGs achieve the above objectives not only by pooling their savings regularly but also by getting a series of empowerment and capacity building trainings. These trainings include entrepreneurship skill development, business planning, SHG bookkeeping, HIV/AIDS and others STDs, leadership \& management skill development (SHG Leaders) Basic literacy program (to Illiterate SHG members) and personal and environmental hygiene, and Participatory rapid appraisal (PRA) technique (SHG Leaders). In the light of the above views, this study addressed the following research questions.

- Are involvements in SHGs able to change the economic capacity of destitute women through achievement of the objectives stated above?

- Are SHGs independently able to manage their savings, and loan to run their business projects?

- Are the trainings able to improve the role of participation of the poor women at family and community level?

The Objective of the Research: The goal of the study is to evaluate the overall impact of SHG approach on beneficiaries at household level

\section{The Specific Objectives of the Research}

- To investigate if the economic aspects of the beneficiaries at household level demonstrated improvement

- To assess if SHG approach has brought the desired results on the lives of the beneficiaries in the social, political and leadership aspects of their lives.

- To recommend if SHG could be adopted as a development model for mitigating poverty at the national level.

Limitations of the Research: The study was subject to the following limitations.

- Time and resources contributed to limit the research from being comprehensive enough.

- The fact that SHGs did not have a periodic and consistent system of records of their performance and improvements has limited access to get reliable and accurate data.

- Some respondents withdrew themselves from the research and were not willing to give the necessary information regarding their personal lives which were required for the study.

- Two of the 12 SHGs which were planned to be covered by the study were already terminated due to lack of unswerving commitment from members.

\section{Literature Review}

Overview of Poverty in Ethiopia: According to UNDP Human Development Report (HDR) 2011, 39 percent of Ethiopian Population lives below income poverty line (UNDP, HDR, 2011 PP 5). According to UN report 2001 quoted by Bezabih Tolosa, in his thesis, women comprise a majority of those living in absolute poverty. 
Gender differentials persist at all levels and women disproportionately bear the burden of poverty, which is mainly attributed to a lower social status given to them and the resulting powerlessness, and discrimination against them in terms of access to and control of resources and opportunities. Women also experience a lack of access to leadership and other decision-making positions, while coping with exposure to violence of varying magnitudes including domestic violence, which is traditionally considered as acceptable and is treated as a family affair, etc ( Bezabih, 2007, PP 6).

Initiatives taken to address women's Problems in Ethiopia: Women are the most vulnerable segment of the society at any levels. In fact the magnitude of the problems that women face depends on country's socioeconomic condition and the level of consciousness of its people. It is the interplay of many factors that make women subject to different economic and social problems. In order to address the problems that Ethiopian women are facing from time to time, the Ethiopian government and many other not for a profit organizations have initiated different developmental endeavors targeting destitute women from the poorest section of the society. One of the development endeavors that has long-lived and was common in Ethiopia was credit and saving cooperatives in which beneficiaries would take a loan from the organizations interest free and invest into different kinds of small scale business activities. Past experiences show that these women who were part of this program could barely save out of the small profit they would make. Most of them could even find it hard to return their loans successfully at the designated time. As the result many of them faced legal measures by the organizations from which they took loan. Development scholars agree that this is because the beneficiaries do not have part in the process of pooling the financial resources. Since the beneficiaries would not contribute to the fund, they would not have sense of ownership that would make them loyal to the bylaws formulated by the organizations from which the fund comes.

It seems that it is due to this negative incident that nowadays, quite a good number of NGOs are making a paradigm shift to SHG approach which, unlike other approaches, involves groups of 15-20 people who voluntarily form a group and start saving money. When a sufficient amount of money has been saved, members can take out loans to set up small businesses and those most in need are prioritized. As a result of this work, a good number of people has now improved their livelihoods and together is lifting themselves out of poverty. Ashenfi (2011, PP 12) in his theses writes that, the past experience on community empowerment was based on credit and saving and giving some amount of money as seed money/free handout/ for beneficiaries to bring change. But the SHG approach is totally different from this approach because the process or framework is established on people's attitude and their resource. Its structure is also different. By this approach they encourage the beneficiaries to take full responsibility on decision making, leadership, facilitation, internal lending etc. Bezabih( 2007, PP 15) states that "many researchers, who studied the benefits of SHGs, found out that SHGs provide Considerable social protection and income opportunities to the members; and accordingly have acquired prominent status in maximizing social and financial returns. “

Development versus Aid: Long term studies show that foreign aid has become a hindrance to development instead of becoming a blessing as it was professed by many aid recipients. In fact, there is inverse relationship between development and aid as it is described in the table below.

Table 1: Comparison between Development and Aid

\begin{tabular}{|c|c|}
\hline Development & Aid \\
\hline It is sustainable & It is only for a short time \\
\hline It solves problems permanently & It is needs-based \\
\hline It helps people to become self-reliant & It inclines to building dependency syndrome \\
\hline $\begin{array}{l}\text { It focuses on building the capacity of people through } \\
\text { capacity building trainings. }\end{array}$ & It views people as recipients \\
\hline It meets people's perceived needs & It meets immediate needs \\
\hline
\end{tabular}

SHG is a model for ensuring sustainable development because it makes the destitute stand for a mutual goal of helping each other to deal with their problems with their own resources available at hand without expecting foreign aid from outside. It also makes them believe that their problems cannot be solved by outsiders who do not know the nature of the problems, and they are the solutions to their own problems. Since SHGs can also be community platforms from which people especially women become active in village 
affairs, stand for local election or take action to address social or community issues, the approach is in line with the development concept that results in change on the lives of the poor in a sustainable manner.

Concept of Self Help Group Approach: A Self-Help Group (SHG) is an informal association of people in a village, hamlet or urban neighborhood. Self help Group (SHG) is an association of poor persons/weaker sections in a community with a common objective of working together for their economic and social development and also for their overall community development. SHG approach has certain characteristics that may have little variations depending on the type of societies where it is applied. The size of the group is in the range of 10-20. The members share similar characteristics such as same sex, background or social order, occupation, poverty attributes etc (homogeneity). Members are bound by trust, mutual respect and affection (affinity). Though informal, the group follows sound organizational management principles such as agreed rules and regulations, frequent meetings, maintenance of accounts etc. Mutual help (one for all and all for one) is the guiding principle of the group. Members are guided by the principle of self-help rather than dependence on external help. They are bound together by the collective goal of improving their income and social status primarily through the organizational strength of working together. As the first step towards the above, members make small savings every month. From the common pool thus created, they meet the small credit needs of members who otherwise would have to approach the moneylender. Interest is charged on this small loan, which helps the group to build up its common pool. Members decide the rates of interest and loan repayment installments. The group opens a saving bank account in a financial institution (bank, cooperative society) in which all cash balances, except those that are needed for day-to-day expenses, are deposited. In some countries (it is not yet implemented in Ethiopia), on the strength of its common fund (including savings, outstanding internal loans and interest collections) the group accesses credit from the bank. The group can withdraw money from this credit line as and when its members need credit to start income generating ventures. During its meetings, the group also discusses other common issues and takes up collective action to solve problems of their own members as well as of the community. The group also becomes capable to access support from ongoing development programs sponsored by government and non-government organizations.

Empowerment Aspects of SHGs: Women empowerment is the center of Self Help Group approach. Since many of the target of SHG program are the poorest of the poor who did not have access to formal education, providing training that takes into account the level of understanding of these women is a key strategy of women empowerment. Studies show that the success of any strategy of women empowerment depends upon the following factors.

- Level of education, hard work

- Social custom

- Family planning, small family

- Health, medical services, cleanliness

- Environment, tree growing, kitchen gardening

The Government of Ethiopia and state authorities alike have increasingly realized the importance of devoting attention to the economic betterment and development of women in the country. The Ethiopian Constitution guarantees that there shall be no discrimination on the grounds of gender. In reality, however, rural women have harder lives and are often discriminated against with regard to land and property rights and in access to medical facilities and rural finance. Women undertake the more onerous tasks involved in the day-to-day running of households, including the collection of fuel wood for cooking and the fetching of drinking water, and their nutritional status and literacy rates are lower than those of men. Women's voice in key institutions concerned with decision making is also limited. Key instruments for supporting women's empowerment are self-help groups, whereby 10-20 women from the same village, mostly poor women, come together to contribute bi-weekly or monthly dues as savings and provide group loans to their members. Empowerment trainings for SHGs are rotating around five major components. Economic empowerment, Social Empowerment, Political Empowerment, and institutional Empowerment are the most common ones. Some religious institutions which use the concept of SHG approach for addressing the needs of the poor in their communities include the fifth component, the spiritual empowerment, in the course of implementation. In order to get a full picture of what these components are all about, it is essential to give a brief description of each component. 
The Leadership Aspect of SHG: Leadership is needed generally in the society, in society, government, business and church. If we narrow down the scope, leadership is needed in peer groups, families, work team, task force, etc. In short, it is hardly possible to find a section of a society where leadership is not exercised. Enhancing the leadership capacity of SHG members is part of the purpose of SHG approach because it is generally believed that the success of SHG implementation depends on the quality of the leadership. The question is now, "what kind of leadership is wanted to be practiced among SHG members?" Leadership can be divided as transactional leadership and transformational leadership. Transactional leadership is an old concept of leadership which focused on leadership as exchange process which promises rewards to followers in exchange for performance where as a transformational leadership is a newly developed concept of leadership that can be taken a kind of motivation which raises the consciousness of people about what they want. Reverend Megeresa Guta elucidates on the definition of transformational leadership in the light of what Bernard Bass said. Megeresa compares and contrasts the difference between transactional leadership and transformational leadership as follows. Transactional leaders accept what can be talked about where as transformational leaders' change what can be talked about. Transactional leaders accept the rules and values; transformational leaders change them. Transactional leaders talk about payoffs; transformational leaders talk about goals. Transactional leaders bargain; transformational leaders symbolize (Megersa Guta (Rev). According to Megersa, in general, the transformational leader motivates to do more than we are expected to do by raising awareness of different values, by getting us to transcend our self interests for the cause, and by expanding our portfolio of needs and wants (Megersa).

In the light of the discussion above, transformational leadership is the most appropriate and pragmatic model of leadership for ensuring transformational development. Ashenfafi concludes that it is possible to build a model of leadership that more accurately predicts a leader's ability to influence individual as well as group behavior within appropriately defined time intervals by examining leadership according to time and interand intra-individual change. Ashenafi also adds that the role of leadership in empowering people is a crucial process that helps to build followers commitment and inspiring better performance (Ashenafi, 2011 PP 49). It is, therefore, essential to point out that transformational leadership is to be practiced more than transactional leadership among SHG members because of the fact that former focuses on motivation of people which raises the consciousness of people about what they want unlike transactional leadership that expects the people to comply with certain rules and values. Since the level of awareness of leadership of most of the SHG members is very low and the groups are homogeneous with respect to their statuses in the society, it is very difficult to make them obey their leaders in the mentality of boss-subordinate relationship. Instead of expecting the members to observe certain rules and values, and reward them in exchange for their performance and punish them when they fail to comply with the rules and values, it is suggested that participating them in the process of making the bylaws and course of implementation would be of paramount importance for ensuring effective leadership among members of SHG.

Saving in SHG: Since saving is the pillar for economic growth and the basic foundation for investment, SHG'S basic philosophy focuses on enhancing the saving capacity of the poorest of the poor who are target of this approach. However, there is this stereotype among the community that the poor have nothing to save because they live a hand to mouth life. It is generally believed that saving from subsistence economy is impossible. But economic theory does not teach that saving is limited only to the rich who have already been able to meet their basic needs and struggle to meet their safety or security need for the future. It would rather assert that saving at any level of society is possible. The theory further elaborates that there are other determinant factors such as overspending that that reduce the saving capacity of the poor instead.

SHG Linkage to Formal Finance Institutions or Banks: Another important feature of self-help groups has been the establishment of links between self-help groups and the formal microfinance institutions and commercial banks. Studies show that creating a link between SHG and microfinance institutions enhance the loan capacity of SHG members and accelerate the time when they take loan. Banks could set up their own inhouse NGO to support these efforts. Loans are provided only to the groups, not individuals (although the groups normally on-lend to individual members). In addition to lending to self-help group, which is profitable for the bank, supplementary businesses could be brought in through self-help group members opening deposit accounts and taking loans as individuals. The impact of the commercial banks' links to self-help groups is attested to SHG members who have become beneficiaries from SHG-bank link. 


\section{Research Methodology}

Research Design: The research methods or designs that were employed in this study were both quantitative and qualitative. However, the quantitative method used in this study is quite simple statistics expressed in terms of percentages and frequencies; and they are used to give explanations on the demographic and socioeconomic characteristics of the study subjects. In order to validate the data analyzed by quantitative method, the study also used qualitative technique in which case studies and survey questions were employed frequently and predominantly among other qualitative techniques.

Sampling Techniques: As it has been stated earlier, the research methods used in this study is both qualitative and Quantitative. The sampling techniques used to select samples for this study was a mix of simple purposive sample and systematic sample techniques taking into account the maturation of the groups. Since it needs somewhat reasonable number of years of maturation to see the impact s of the SHG approach on the lives of the beneficiaries, it was, therefore, only those whose maturation was two years and above were selected for impact assessment.

Sample Size: As it has been stated above, the sample size selection took into account the group maturation. From those groups whose maturation is 2 years and above, two members were selected randomly from each group of members ranging from 15-20 (10 to 13 percent of the total population, 187 members of 10 SHG groups) for interview and filling out questionnaire. In selecting the sample of the study from the SHGs, other factors that were taken into consideration were capacity of the group in terms of knowledge level and vibrancy of group members.

\section{Findings of the Research}

The Saving Patterns of SHG: Studying the saving pattern of SHG members was one of the focal points of this research. The study assessed the saving pattern of SHG members whose maturation level was two years and above. It was found out that the average amount of regular saving that an individual member saves per week is Birr 4, and the average amount of group saving per week is Birr 40. In an informal discussion held with focus group, it was learned that their SHG bylaws allow interested members who are willing to save beyond their regular savings. These are called 'special savings' which are intended to boost their group saving capital. The study also reveals that there were other sources of income by which SHGs augment their group capital some of which were fee collected from members who do not comply with the bylaws, interest collected from loan takers, and incentives given by visitors from different organizations. The following table provides detail information about the saving pattern of the respondents who were taken as samples for the study.

Table 2: The Saving Patterns of SHG Members

\begin{tabular}{lll}
\hline $\begin{array}{l}\text { Average amount } \\
\text { Birr Since 2010 }\end{array}$ & saving in & $\begin{array}{l}\text { Total } \\
\text { No }\end{array}$ \\
\hline $250-400$ & 12 & $\%$ \\
$400-550$ & 6 & 30 \\
$550-800$ & 2 & 10 \\
Total & 20 & 100 \\
\hline
\end{tabular}

Source: Field Survey

According to the data tabulated in the table above, the percentage of respondents whose amount of saving fall under the category of $250-400$ is $60 \%$ where as the $30 \%$ of the respondents saved in the range of $400-550$ in the life time of the SHG up until the time when this survey was conducted. It is also noted from the table that only $10 \%$ of the respondents' savings full under the category of 550-800. A random assessment of some SHG members' passbooks where their individual savings are recorded show that some SHG members have saved up to Birr 2000 at the time of this survey. An assessment was also made on the account books of all SHGs, and it was found out that the highest group saving was Birr 18,000 and the lowest group saving was Birr 3,800 at the time of the survey. The total saving of all the ten SHGs covered under the study was 93, 000 at the time when this assessment was conducted. Though the group savings of almost all SHGs covered under the study was in an increasing order for the first few months, an assessment made on some SHGs has shown that group 
savings was declining from some time onwards. It was reported by the respondents that fact that the number of some SHG members decreased from time to time for different reasons has caused the group savings of some SHGs to drop gradually. In indirect questions presented to some of the respondents, it was found out that the members know clearly the objectives of saving. Some of the objectives of saving pointed out during the discussion were ensuring social security, ensuring food security, providing education to children, getting appropriate health services, developing loan capacity and expanding business, celebrating holidays without getting into unnecessary debts, and ensuring security funds for times of emergency and building assets. According to the report of the respondents, all the beneficiaries have been able to meet the objectives of saving partly or fully. They also reported that the fact that they have committed themselves to saving has spared them from being victims of loan sharks.

Impacts of Trainings: Training is the backbone of the Self-Help Groups. This is a movement to empower women socially, economically, and politically through capacity building of the poorest and the most disadvantaged (Gariyali \& Vettival, 2004; P 59). Members of SHGs should take series of trainings that include SHG awareness trainings before they are organized under the umbrella of SHG. Other components of the trainings include saving and loan management, basic business skills (BBS), basic business skill development (BBDS), Social empowerment, family planning, hygiene and sanitation. The trainings are believed to be vital for building the capacity of SHG members, and empowering them in terms of bringing changes of attitudes. The assessment made on members of SHG has shown that the trainings they took thus far has brought positive impacts on their lives and consequently has enabled them to change the course of their life styles.

Benefits of Becoming SHG Members: Studies on SHG beneficiaries show that the majority of SHG members benefit from becoming SHG members. In order to examine the benefits that SHG members obtained from becoming members of SHG, queries that measure the qualitative impact of SHG on the lives of the beneficiaries were presented to some randomly selected members of SHGs. It was found out from the replies of the respondents that participating in SHG activities has earned the beneficiaries a great deal of benefits. When asked what the changes demonstrated in their lives looked like after their involvement in SHG program, all of the respondents replied that they were in a better status in many aspects than their previous lives and they were able to see many more positive changes after their involvement in SHG program.

\section{Conclusion}

In the light of what has been described and analyzed in the findings above and the observation made during the visit, the overall progress of the SHGs is good. However, it was seen that there remains a lot to be done to bring the SHGs up to the desired level of empowerment sought by the organization. An interview made to some SHG members reveal that there exists a big gap that needs to be filled in as far as proper and consistent follow up was concerned. Some members of some SHGs have made their opinions crystal clear that they needed something to motivate them because they are very much frustrated because of the small loan capacity of SHGs due to the small capital accumulation. It, is therefore, imperative to think of other ways that that their capital could be enhanced. It requires for further research to be conducted to find out whether capital injection/ providing seed money at the initial stage of SHG formation could help to enhance the group capital. Giving per Diem to SHG members when they participate in trainings is also another issue that was being circulated among the members. This issue also needs further research to find out wheatear paying per Diem to participants in the training has a positive or a negative impact on the lives of beneficiaries. Apart from weak market linkages in the context of income-generating activities, there are also a few other concerns in relation to women's empowerment. First is the capacity building of self-help groups, which are in need of support in accounting, financial management, and organizational development. The second concern is about the gender focus in urban financial services. It is, therefore, essential that CHSFS has to find ways in collaboration with the local government to help the SHGs create market network across the board and develop their loan capacity through creating SHG-bank linkage where they could get financial services.

With a coordinated and integrated support of CHSFS and the local government, and by working together in Self-Help Groups, SHG members can develop their financial capacity in a relatively short period of one to three years. As far as their group savings are concerned, there exists big variation in the amount of their savings. According to the assessment, the maturation age of the groups is almost similar and therefore there 
was no significant difference of time of maturation as such. It is therefore imperative to make further investigation to find out why such discrepancy existed and how SHGs with lesser amount of savings could learn from those SHGs with higher amount of savings. The findings of many researchers who conducted studies on the socio-economic impacts of SHGs revel that involvement in SHGs have significant economic and social contributions on the lives of poor women. One last remark that should be worth noting here is that there should be further discussion with the SHGs which took skill training as far as the impacts are concerned before proceeding with providing other skill trainings to other SHG members. This can help to create success models which could motivate others to participate in subsequent trainings.

Recommendations: In the view of the above discussion, the researcher will provide the following recommendations to CHSFS and other SHG implementers as these are believed to benefit them to become more efficient.

- Primarily, the CHSFS needs to make sure that SHG members clearly understand the vision, mission, goal, and objectives of the project.

- Trainings should be given on the scheduled time and periodical follow up should be conducted.

- The organization is also expected to work more on expanding its scope to incorporate more poor women to SHG program.

- The organization should apply participatory approach (not top- down) whenever there are issues to be implemented on SHGs.

- should take initiative to create a forum where pertinent governments could involve to come up with the same terms as far SHG is concerned and then recommend that SHG approach could be adopted as a development model for mitigating poverty because institutionalizing SHG approach at national level will accelerate the time when transformational development is aspired to be achieved

- SHG consortium should facilitate for forum on which SHG implementers will discuss to come up with a consensus on disputable issues such as per-Diem and capital injection.

\section{References}

Ashenafi, E. (2011). The role of leadership in people's empowerment: SHG in focus in the case of WSG/hope chencha banner no.000624060: a thesis submitted to university of Greenwich and international leadership institute in partial fulfillment for the degree of master in transformational leadership and change October 2011.

Bezabih, T. (2007) Assessing the socio-economic impact of self help groups: a case to Ethiopian kale heywet churchnazreth integrated urban development project, the school of Graduate Studies of Addis Ababa University In Partial Fulfillment of the Requirements for the Degree of Master of Arts in Social Work (MSW), Addis Ababa, Ethiopia

Gariyali, C. K. \& Vettival, S. K. (2004). Women's Own The Self -Help Movement of Tamilnadu, Vetri Publishers, New Delhi, India.

Megersa, G. (Rev)-Course writer, Course Editor: FAEM Editorial Board, Christian Leadership (MBA 617) for MBA students Publisher: FAEM: Ethiopia Addis Ababa

Solomon, M. (2008). Socio-Economic Baseline Survey of The Hadiya Zone: A study commissioned by Children's Home Society and Family Services, Nov. 2008

UNDP Annual Report. (2011/2012). United Nations Development Program, January 23 available at < http:www.undp.org: One United Nation Plaza New York NY 10017

UNDP-Human Development Report. (2011). Sustainability and Equity: A Better Future for All Explanatory note on 2011 HDR composite indices Ethiopia. 